\title{
A Call to Responsibility
}

\author{
Marcel Bursztyn, Melissa Curi, Carlos Hiroo Saito
}

doi:10.18472/SustDeb.v11n2.2020.33457

The literature is lavish with publications on the double characteristic of times of crisis. A recurrent image (and controversial) in texts is that of the Chinese ideogram, which combines expressions of risk and opportunity. It is controversial because Mandarin scholars consider this transliteration is not genuine. Nevertheless, the allegory is convenient.

Crises are times when dangers are most latent and also opportune moments for bolder decisions that can lead to solutions. In other words, they are drivers of change and can lead to progress in different spheres. But, they can also engender tragedies.

The pandemic of Covid-19 which has befallen the world this year, 2020, is not over and is already showing us lessons, good and bad. Among the good ones, it is worth mentioning the remarkable mobilization of science and the realization that this is the best way to anticipate and face threats to life on our planet, and also the evidence that we must act with a broader vision than just the short term one.

Never has the notion of sustainability, in its most exhaustive, durable and radical sense, been so crystalclear! Among the bad lessons, there is an ordeal of examples: the denialism of science; the short-term selfishness of those who do not give up the immediate profitability of their investments (even if this implies risks of future losses); the dismantling of the Welfare State; racism and other forms of social exclusion and the emergence of discourses (political and pseudoscientific) of charlatans, who launch and propagate miraculous formulas of solutions without any scientific basis.

All this happens at a very particular moment in history. Covid-19 arrived quickly and soon spread, due to the massive movement of people and goods around the world. A world, marked by the rise of rulers that are eager to put into practice ideas that go in the opposite direction of ideals of well-being, solidarity, peace and responsibility, which seemed to be legacies of the 20th century.

The great environmental crisis of industrial society has led to a mobilization of the growing sectors of society, to make the State, worldwide, a key player in ensuring ecological balance, quality of life and the environment in general. Since the United Nations Conference on the Human Environment, held in 1972 in Stockholm, the theme has gained a planetary dimension. Gradually, each country was creating its institutional structures to deal with the environment, and several international protocols and laws have been established. But, the 21st century has brought negative surprises, especially in recent years. Two examples are eloquent.

First, the election of tycoon Donald Trump in the United States represents a milestone in the inflexion of ideals that seemed to be legacies of the previous century. Early on, Trump appointed to head the EPA (the country's Environmental Protection Agency), a prominent climate change sceptic (Scott Pruitt), who tried to minimize the regulatory role of that agency. Due to allegations of scandals, Pruitt had to resign in 2018, being replaced by Andrew R. Wheeler, a well-known coal industry lobbyist.

The second example comes from Brazil. The election of right-wing extremist Jair Bolsonaro, who assumed the Presidency of the Republic in 2019, represented a negative shift in the relevance of controlling deforestation, protecting indigenous peoples, enforcing legislation on environmental 
crimes, control over the use of pesticides, among other setbacks in addressing the environmental issue. Bolsonaro, who had already fined for violation of environmental standards, chose to dismiss the head of the National Institute of Space Research - INPE, an internationally recognized body for its competence when it showed the alarming data on deforestation in the Amazon. In the tellings of the one chosen for the role of Minister of the Environment, the government should take advantage of the opportunity opened by the Pandemic of Covid-19, with the press focusing on the theme of health, to literally "open the gate" and "let the buoy pass", alluding to the deconstruction of regulatory instruments and environmental protection practices.

These are two worrying examples, which, unfortunately, cannot be seen as isolated cases. The attitude of some political leaders in the face of the pandemic also reveals the lack of empathy and responsibility with exposing people to a disease that can be lethal. Populist temptation seduces tyrants, adventurers and opportunists. Boris Johnson, in the UK, was only convinced of the seriousness of the problem when affected by the disease. Trump strives every day to deny reality and tries to shift the responsibility for the effects of caution to governors who oppose him. In Belarus, the tyrant Lukashenko, in power since 1994 , mocks the severity of the pandemic by suggesting that the best prevention is the combination of sauna and vodka. In Brazil, Bolsonaro insists that the use of chloroquine, which science has proven to be ineffective and to bring real side effects, solves what he considers a "little flu".

The discourse around the fact that measures to combat COVID-19 would undermine the economy, which would be allegedly exaggerated and unnecessary, shows a version of necropolitics outside the contexts of militarized warfare. A genocide is underway which by the way, is selective.

Never have the principles of responsibility, precaution, and prevention, so dear to sustainable development, been so current and imperative! Never has the concept of inclusion and respect for the life of humankind, been so necessary.

In this difficult moment of serious risks and necessary responsible action, Sustainability in Debate launches, in its second edition of 2020, nine articles in the thematic Dossier "Environmental Systems Modeling and Landscape Management" and four articles in the Varia section, presented below.

The first article of the section Varia is titled "Linking migration, climate and social protection in Brazilian semiarid: case studies of Submédio São Francisco and Seridó Potiguar " and proposed by the authors: Ana Claudia de Almeida, Alisson Flávio Barbieri and Saulo Rodrigues Filho. They analyze the link between droughts, migrations, and social protection in the Semiarid region, based on the conceptual discussion around two case studies: The São Francisco Submédio and the Seridó Potiguar.

In the article "Short-term effect of adding $\mathrm{N}$ in the urban rainforest ", the authors Bruno Moraes Nascimento et al. present the results of an experiment carried out to investigate the effects of nitrogen addition on soil respiration during five days in the Tijuca Forest.

Authors Victor Marchezini et al., in the article "Emergency funding public policy for disaster response in Brazil from 2013 to 2017", based on data from the Decrees of Emergency Situation and State of Public Calamity and the costs of disaster relief and response in the country, assess the use and expenditure of these public policies.

Finally, the article "Climate change and the unsustainable urbanism in the municipality of João Pessoa, Paraiba, Brazil", by the authors Letícia Palazzi Perez, Andrea Leal Porto Sales and José Augusto Ribeiro da Silveira, based on spatial data from the recent deforestation of João Pessoa, analyzes the legal and socio-environmental characteristics of the city's urban sprawl and how municipal urban and environmental policy have catalyzed processes of socio-environmental injustice.

The Editors 